CLINICAL ACCOUNT

of

\section{TWO CASES OF TRAUMATIC TETANUS SUCCESSFULLY TREATED WITH THE ORDEAL BEAN OF CALABAR.}

By EBEN. WATSON, M.A., M.D.,

IECTURER ON PHXSIOLOGY IN ANDERSON'S UNTWERITY, AND SURGEON TO THE ROFAL INELRMARY, GLASGOW.

Some years ago, when the peculiar effects of the Calabar bean were made known in this country by missionaries and others who had resided in that part of Africa, it occurred to myself and to several surgeons, amongst whom I may mention the late Professor Miller, of Edinburgh, ("System of Surgery," p. 515,) that it might prove useful in the treatment of tetanus; but, so far as I know, this suggestion has not hitherto been acted on.* When the first of the following cases occurred in my hospital practice, I thought it a good opportunity of testing the practical truth of these ideas, which had long been floating in my mind, because the spasms were so severe at the period of the patient's admission, that it was obvious she could not long endure them unless they were at once mitigated. Besides, soon after beginning this treatment, I had the high sanction and encouragement of Professor Christison, who had in his own person felt the potent influence of this remarkable poison.

Without further preface I shall now relate the cases, with, at present, only a few explanatory remarks, as $I$ am anxious for their speedy publication, in the hope that others may be encouraged to give this druy (which I may now call it) a further and a fuller trial than I have yet done; for I believe that the success which I have met with in the treatment of these two cases holds out a fair promise of our being thus led to a powerful and yet manageable remedy in a class of cases notorious, heretofore, not only for their fatality, but also for the total absence of any rational means of controlling their rapid and distressing progress.

Case 1.-Annie $W$ - aged eleven years, admitted to the Royal Infirmary on the $12 \mathrm{th}$ of November, 1866. About three weeks agot the patient struck her right foot against a stone and bruised and cut it slightly at the side of the nail of the great toe. No attention was paid to it at the time. She has at present the aspect and expression of one who has trismus, and she opens her mouth with difficulty. For this "lock-jaw," which commenced six days ago, she has been sent to the hos pital.

She remained in this state, and no violent spasms came on till the evening, when opisthotonos occurred in a very severe form, the body being bent into an arch of nearly three-quarters of a circle. She was so rigid in this state that my resident assistant, Dr. Forsyth, administered chloroform by inhalation, which relieved her for the time, but whenever she came out of the anæsthetic state the spasms were renewed as violently as ever; so much so, indeed, that she was again put under its in fluence with the same temporary good effect. While under the chloroform the outer half of the toe-nail was cut away from the still inflamed and ecchymosed matrix, and a poultice was applied.

Nov. 13th.- This morning I found her as described. Her jaws were firmly locked, and her body and limbs perfectly rigid. The tendency to opisthotonos was at once induced by the patient's attempting to drink cold water, and also by touching any part of her. Indeed, even though undisturbed, the spasms were very frequent, and always tended in the direction of opisthotonos; hence the poor child found her only

* Since writing the above $\mathrm{I}$ have discovered, when looking for something else, a case of tetunus related by Mr. Holmes Coote in THE LANCET for March $26 \mathrm{Lh}$, 1864, " in which the Calabar bean was freely administered." $\mathrm{H}$ very properly does not say that it was treated with the bean; for although the patient took the extract for nearly two davs, yet no appreciable effect was produced. It was therefore given up, and other remedies employed. If the case proves anything at all, it is the tolerance which tetanic patient have of this powerful agent, and $r$ believe that it was not pushed fur enough, notwithstanding its free administration. The warrant so to push it can only be found in experience, and hence I feel the more, not the less, bound to record the two eases which have occurred to me.

t The account of the cases is taker, with only a few verbal alterations, from the hospital journals. comfort in lying on her belly, with her head and shoulders over the edge of the bed; and at this time she required continual attention to prevent her falling out of bed, and as the spasms were coming on, her cries for help were most distressing. I prescribed a dose of calomel and jalap at once, and during the day, every two hours, fifteen drops of the tincture of cannabis indica, a drug which certainly soothes in tetanus more safely than any other.

14th.-Patient's bowels have not been moved by the calomel and jalap. She continues in the same state as yesterday, but in the evening the spasms became much more severe. She was ordered half an ounce of castor oil with a drop of croton oil mixed with it.

15th.-Bowels acted freely yesterday; stools quite black. She has taken the Indian hemp very irregularly, sometimes spitting it out.

Every evening there is a considerable aggravation of the spasms, and this seems to be more and more marked each successive evening.

I now determined to try the Calabar bean, and in the emergency the only preparation of it which could be got was that used in ophthalmic practice for contracting the pupil. I may here mention, for the sake of those who may not have had their attention called to this subject, that the action of the Calabar bean in sufficient doses is to paralyse the voluntary muscles, the very muscles which are spasmodically contracted in tetanus. Hence the prospect of counteracting the influence of the disease by that of the poison. I may also state that the action of Calabar bean in contracting, and that of belladonna in dilating, the pupil cannot at present be satisfactorily explained. We can only assume that in the former case the radiating fibres of the iris are paralysed, and in the latter the circular; but whether this is due, as Valentin has supposed, to the special distribution of the cerebral and sympathetic nerves to these different sets of fibres in the iris, and to a special action of the two substances upon them, it is not easy to determine. On this point I may hereafter enlarge a little; but in the meantime I return to the narrative of my case.

At half-past two P.M. of the 15th November, one square of Squire's gelatine paper, containing the extract of Calabar bean, was put on the patient's tongue through the space left by a missing tooth. Shortly after getting it she felt easier, was more cheerful, and kicked up her heels as she lay in bed on her abdomen, to show the power she had over them. At three P.M. she got two other squares, at seven P.M. three squares, and at ten P.M. two more. No severe spasms occurred during this evening; she had only a few short starts, but she was always very rigid in both body and limbs, and the opisthotonos and trismus were quite marked. She was more cheerful, however, and spoke more distinctly. Pupils rather contracted. She was to have two squares of Calabar paper every hour during the night.

16th.-This morning I found her quite rigid, and with frequent and severe spasms. In fact, I thought either that the papers were not sufficiently strong, or that they were losing their influence on the patient. I now therefore ordered the following preparation:" Extract of Calabar bean, twelve grains; white wine, one ounce. This made a maddy sort of wine of the Calabar bean, every five drops of which contained aboat one-eighth of a grain of the extract. Such a dose was to be given every half hour, the effects being carefully watched by my assistant. It will be noticed that the doses were given very close together, for we had already learned that their effects were very short-lived. These doses were regularly given till seven P.M. by which time she had taken eighty drops or two grains of the extract. Only momentary twitches had occurred, and these principally when spoken to. At halfpast seven P.M. she was in a semi-comatose condition, lying on her back, with no arching, mouth open, pupils pretty well contracted, breathing quiet and regular, pulse rather hurried and full.

In this state of things the Calabar bean was intermitted for two hours and a half-i. e., till half-past nine P.M, by which time the pupils had again dilated, and transitory spasms were induced by tonching or rousing patient with questions. Nine drops of the wine were then given, and five drops thereafter every hour during the night.

18th. - She continues better, breathes more easily, and wallows better; pulse 84, of good strength ; pupils natural. Increase the dose of the wine to ten drops every hour.

* None of these preparations of Calabar bean were left in the ward, bat were kept locked up, and administered either by my assistant, a fully qualified gentleman, or under his superintendence by the nurse of the ward, who is a most careful and attentive person. 
19th. - Notwithstanding this increase, the patient had three severe fits of opisthotonos early in the morning, and she remained very rigid and the spasms easily excitable till my visit. I now determined to use a stronger dose of the extract, and thus endeavour to conquer the disease. For this purpose I ordered the following pills :-- Extract of Calabar bean, twelve grains; ginger powder of sufficient quantity to make twentyfour pills: one to be taken every hour. By mistake the apothecary made these pills of twice the strength ordered-viz., containing each one grain instead of half a grain of the extract. This was not, however, discovered till the evening, so that the patient took one grain of the extract every hour for eight hours without any particular effect being produced. But half an hour after the ninth had been swallowed, the patient fell into the following state:--Her eyes were widely opened, staring and glassy; the pupils were contracted to pin points; the pulse was rapid and intermitting; there was a mucous rattle in the throat, and the breathing was jerky and fitful. Patient did not answer questions, and gave no sign of sensibility. She had no spasms, neither could they be induced. In fact, all the muscles were completely relaxed, except those of the back, which were still rigid. She either could not or would not move any of her limbs, or make voluntary efforts to swallow. Some brandy-and-water and seven drops of the tincture of belladonna were poured down her throat, she not resisting, and this was repeated in five minutes. No effect was produced on the pupils, but the expression became less death-like. Patient was turned over on her side, for she had lain on her back hitherto, and then she got quit of some reddish-coloured, apparently bloody mucus from the throat by both mouth and nose. The breathing was thus rendered easier, but it was at first very hurried and panting. Gradually it became fuller and slower, and the pulse likewise became slower and more regular. The pupils soon dilated, but the extremities remained quite flaccid during the greater part of the night. As soon as the breathing was partially restored, she seemed to be quite sensible, but averse or unable to move. Towards morning the spasms, though less violent, could be easily induced; and next morning, at half-past eight, I found no traces remaining of the very remarkable state in which she had been on the previous evening. She was, however, flushed and perspiring; the pupils were quite natural, but the pulse was quicker than formerly; it numbered 108 in the minute, but was soft and regular. She expressed herself as better. She had no giddiness or any other disagreeable feeling attributable to the Calabar bean, and she was perfectly correct in her mind.

I remarked that the arms, though still unnaturally stiff, were more under the control of the will than they had been. She could move thern a little, and she could separate her teeth just enough to get the edge of a spoon between them. She could also swallow better, and she lay much more quietly, and now generally on her side, in bed.

I considered it prudent to cease giving the bean to this patient for a time, and allow her to rally quite thoroughly from its effects. I therefore stopped it, and once more ordered the tincture of cannabis indica, with appropriate food and stimulants. Under this treatment she improved in strength, but not much in respect of the tetanus. Her spasms certainly never were so strong as formerly, but they were very easily produced, showing that the disease was still unconquered. Besides, the body and legs became again quite stiff, so that if one could have raised her by the foot, he could have held her straight out in any position. At the same time the face had rather a more natural expression, and she could separate the teeth about half an inch. Her power over the arms was also greater, and she could even move the head a little to one side.

Such was her state at the end of the ten days during which she had no Calabar bean. It seemed to me that the tetanus had received a decided check from the large dose of the bean taken on the 24th of November, and that it had never since assumed its former severity. Still there had been little further progress made towards a cure since the bean wâks stopped. I therefore recommended it in the form of tincture, made after the receipt of Dr. Fraser (Edin. Med. Journal, vol. ix., p. 124), who considers five minims to be equal to three grains of the kernel.

Dec. 6th.-I ordered the patient to have a dose of five minims of the above tincture every two hours, stopping the cannabis indica.

10th.-Last night without any aperient medicine having been given to her, patient had five large watery evacuations from the bowels. This was the more remarkable because she had previonsly required a strong dose of castor oil, often fortified with croton oil, to more the bowels, and except from the effect of such medicine, they had always remained confined. I have little doubt, therefore, that this was another of the phy. siological actions of the bean-viz., catharsis.

It was noticed likewise to-day that her muscles generally were much more relaxed. The expression of the face was much more natural; she could laugh and open the mouth wider than she had yet done, and she could chew her food well. Her head and limbs, both superior and inferior, were likewise capable of being moved a little; but her back and abdomen still remained rigid, and the spasms, though very slight, were easily reproduced. The tincture was continued in the same dose, but only every six hours.

After this date her recovery was very rapid, and I find it noted in the journal on the 22nd December that for some days previously the patient had been quite well, and running about the ward. No trace remained of her formidable illness, and from the above-mentioned day she took no more of the bean.

On the 4th of January, 1867, she was sent to the Convalescent Home at Bothwell.

CASE 2.-John M'P-_, aged thirteen, admitted on the 6th of December, 1866. Three weeks ago patient's left forefinger was drawn in between two pinion-wheels, and the nail was bent backwards, while the side of the finger was slightly torn. The wound was dressed by a surgeon that day. Next day the boy pulled away the nail, which was loose, and the wound healed up in a week. On the evening of Dec. 4th patient first felt a pain in his back and stiffness in his legs. On being closely questioned, he admits that shortly before he felt the pain in his back he had been trying to turn round, and fell backwards, cutting his ear slightly. After lying down in bed that night he says he took starts, which raised up his back. This was the commencement of tetanus. All this time patient had been very confined in his bowels. He had no passage for a week after the accident, when he had one motion. A week after this he got a dose of castor oil, which purged him; and from that time till the present date he has again been confined.

On admission, the tetanic symptoms were well marked. The trismus was so decided that he could only open his teeth for about half an inch. His back and limbs, superior and inferior, are reported as quite rigid; and any slight exertion, such as trying to open the mouth, brings on a spasm which twitches his head backwards in a slight fit of opisthotonos. Complains of indistinctness of vision at a short distance. Right pupil much dilated, but sensible to light. To have a draught consisting of half an ounce of castor oil and one minim of croton oil.

Dec. 7th. - The oil acted twice yesterday and thrice this morning. Pulse 84, good. To have five minims of tincture of Calabar bean every two hours.

9th.-The doses of the tincture have been regularly taken during the last two days, always with perceptible benefit for about half an hour. During this time patient has slept but very lightly, being easily wakened, and on awaking he has spasms tending more or less severely to opisthotonos. He has taken his food well. Pulse 80, good; tongue white; skin natural. Pupils large, but contractile; right one rather larger than left. Complains of a pain in left side of chest, passing upwards. Heart and lungs healthy. Patient slept but little last night, and is more rigid to-day, especially on the left side of the body. To have four minims of the tincture every hour to-day, carefully watching its effects, and modifying the doses accordingly.

11th.- Had a better night last night than he has had yet; only awoke three or four times. Expression of face is more natural, muscles of limbs are freer, and those of the body are less rigid than they were; but he still takes a general spasm about every quarter of an hour, which, however, is only a third of their former frequency, and they are much less severe than they were. He sat propped up in bed yesterday for a time. Since last report the patient has taken four minims of the tincture every hour. About fifteen or twenty minutes afterwards his pupils are contracted, and from this to half an hour his muscles are in their most relaxed state. These effects seem to wear off very soon, and at the end of the hour the pupils are rather too widely dilated, and the tendency to spasms has increased.

13th.-Was very sleepy yesterday forenoon, and had an in. terval of about an hour between the spasms, which is the longest he has yet had; they are also much slighter, and he can open his mouth about an inch. The muscles of the body are more relaxed. Since yesterday afternoon he has only had five minims of the tincture every second hour, and he had but two doses during the night. 
14th.-Again this morning the dose was given only every three hours, but the spasms became so much more frequent and severe that in the evening it was again increased to six minims every two hours.

15th. - This dose has been continued during the right, and to-day the spasms are again fewer than yesterday, as well as less violent.

16th.-The doses have been regularly given night and day. The patient has not had a single spasm all this day.

18th. - Was out of bed yesterday, and walked, though very stiffly, his back and limbs being less at command than they should be, though not tetanically rigid as before. Thus, he does not in walking bend his knees, but on being asked to do so he bends them quite well. He had only one spasm yesterday, and that was induced by a crutch falling on the ward floor and making a sudden noise, which startled him.

24th.-The above was his last spasm, and in all respects he has continued to improve since last report. He now walks much more freely, opens his mouth, and takes his food well. He takes only six minims of tincture three times a day.

In a few days after the last report the administration of the bean was finally stopped, the patient being in every respect quite well ; and after keeping him under observation for a few days he was sent with the other tetanic patient to the Convadescent Home, on the 4th of January, 1867.

As formerly stated, I publish the reports of these two cases, which I have treated with Calabar bean, that others may be encouraged by my success to do so likewise. There can, I think, be no doubt that both of them were cases of acute traumatic tetanus, the former being the more severe of the two. The disease in both cases came on in the usual insidious way; in the one case taking nearly six days, and in the other two, before general spasms occurred. There can be no doubt that in both cases the patients were in imminent peril

The effects of the bean were very remarkable, being chiefly seen in relaxation of most of the tetanically contracted muscles; indeed, in all of them but the muscles of the back, until far on in the treatment. Then, last of all, these gave way, but slowly, and as it were reluctantly. This was well seen in the boy's case, for his back was stiff for some days after he was able to be out of bed. The effect on the eye, too, was curious. Remembering the speedy and great contraction of the pupil which the bean produces when applied locally to the eye, one could not but be surprised at the slightness of its action on the pupil when given internally. Except when a very large dose was taken, as in the girl's case, the pupil was never contracted so a point. On the contrary, the contraction was very slight and very short-lived under the action of ordinary doses of the drug; and one of the earliest symptoms of tolerance of it shown by the patient was the cessation of even this temporary effect upon the pupil-a tolerance which had to be met by an increase of the doses. Besides, I noticed that after the effect of the bean had passed away the pupil was found to be unnaturally dilated, as if from a sort of reaction of the fibres in an opposite direction.

As to the doses of the bean given in these cases, I must remark that those given in the girl's case were large - too large on that memorable day, the $24 \mathrm{th}$ of November, 1866 . I have already explained how twice as much of the extract was given on that occasion as I had ordered; but I am certain that, though it brought the patient into danger, this large dose checked the disease, which abated from that day. It also affords us now an admirable proof of the power of the bean over this terrible disease, and of the great good to be expected from its more moderate and safe administration. It should be remembered, too, that in tetanus the patient seems to have a wonderful tolerance of many drugs, and that, therefore, larger doses of them than usual may be safely given, and, in fact, are required by such patients before the physiological effects of the medicines are developed. This is well known to be true of opium, cannabis indica, quinine, stimulants, \&c. Now, I think that the Calabar bean is, in like manner, better borne in this disease than it would be in any other. It was taken and required all along, by the girl especially, in much larger doses than I should prescribe in ordinary circumstances. The rule which I should give to others, and the one on which I mean to act myself, is to begin with a small dose, and rather to diminish the intervals than to increase the strength of the dose, till we become better acquainted with this powerful agent. Yet, after all, this is one of those drugs which can only be rightly given in cases constantly under good watching; for its physiological action must be produced else no good result can be expected from it, and to do so a sufficient dose must be given. I know of no general rule that can apply in such a case, but the one of beginning with small doses and increasing them cautiously as effects are or are not produced adequate to counteract the violence of the disease under treatment. I shall only add, in conclusion, that I greatly prefer the fluid form of administering the bean, as giving less probability of its accumulating in the stomach, which might occur if it were given in the solid form - as, for example, in pills repeated very frequently. The tincture, if well made as directed by Dr. Fraser, is certainly the best and safest form in which it can be administered; and five minims of such a tincture is quite a safe dose to commence with in the case of persons above ten or twelve years of age, as far as my experience goes.

Newton-terrace, Glasgow, Feb. 1867.

\section{REPORT OF CASES TREATED AT THE GUARDS' HOSPITAL.}

BY SURGEON-MAJOR WYATT.

(Conctudedfrom p. 237.)

CASE 3.-Spasmorlic cholera, with well-marked collapse; no premonitory diarrhaea; recovery.

J. T_- a a , aged twenty-two, one year's service, previously healthy, was admitted Oct. 4th, at 9.30 P.M., having vomited several times during the previous afternoon only, and also had been purged. His countenance was collapsed ; voice characteristic ; pulse small and weak ; extremities cold ; secretion of urine scanty; complains of intense cramp in abdomen. To have an emetic, and half an hour afterwards thirty minims of chlorodyne; hot bottles to feet; fever diet, and ice to suck.

Oct. 5th.- The purging continues, of a pale rice-watery character; the eyes are much sunken, and features more collapsed. To take two grains of calomel every half hour, with. two drops of dilute hydrocyanic acid, twenty minims of dilute sulphuric acid, fifteen minims of chloric ether, and an ounce and a half of iced water, every two hours. Secretion of urine still continues scanty; pulse very weak and thready. - 1 P.M.: Collapse increased, with great restlessness; eyeballs still more sunken, with dark areola; sickness and watery alvine secretion continue. Ordered, calomel, two grains ; extract of opium, one grain; campbor, one grain: for two pills, to be taken at once; and an hour afterwards a drachm of castor oil in an ounce of peppermint water. The pulse can now be scarcely felt. To take iced milk ad libitum.

6th.-Pulse very thready; surface of body still damp; evacuations whitish; sickness continues. Repeat pill and draught every four hours, also castor oil to-morrow morning; To take iced champagne.

7th. -Slight reaction is now evident; pulse 96 ; skin has an increase of temperature; sickness continues; watery evacuations not so frequent; is very restless and thirsty, but likes the iced champagne. Repeat the pill, and a drachm of castor oil two hours after.

8 th.-More evidence of reaction; still has great thirst, and some abdominal pain ; pulse thready, 100 ; bowels have been purged four times since noon of yesterday, and upon the last occasion contained some feculent-looking fluid; secretion of urine also augmented. Repeat pill and castor oil.

9th.-Pulse 100, stronger; more reaction; still much thirst; diarrhœea and sickness less frequent ; tongue rather dry ; conjunctivæ injected; sleeps a good deal, but is very restless and desponding; voice continues very characteristic. Repeat pill, and castor oil in the morning.

loth. - Passed a considerable quantity of urine, which is natural and free from deposit; evacuations more feculent. To have beef-tea, with two eggs.

11 th. - Slept well, not so restless; pulse 88 , fuller; skin hot, and face flushed; tongue moist ; thirst much diminished; asks for food. Continue mixture every four hours. Repeat pill at night, and castor oil in the morning.

12th. - May now be considered convalescent.

17th.-Dismissed hospital.

Much has been said and written of late with reference to the pathology of cholera, with the view of establishing a line of treatment upon correct physiological principles, and perhaps a greater approach was made during the past year, by careful deductions from post-mortem appearances, than was ever 